\title{
Functions of Root Canal Sealers- A Review
}

\author{
Chanchal Harikishor Rathi ${ }^{1}$, Manoj Chandak², Pradnya Nikhade ${ }^{3}$, Nikhil Mankar ${ }^{4}$, \\ Madhulika Chandak ${ }^{5}$, Samrudhi Khatod ${ }^{6}$, Nidhi Motwani ${ }^{7}$, Arpan Jaiswal ${ }^{8}$
}

\begin{abstract}
${ }^{1}$ Department of Conservative Dentistry and Endodontics, Sharad Pawar Dental College, Datta Meghe Institute of Medical Sciences, Deemed to be University (DU), Sawangii, Wardha, Maharashtra, India. ${ }^{2}$ Department of Conservative Dentistry and Endodontics, Sharad Pawar Dental College, Datta Meghe Institute of Medical Sciences, Deemed to be University (DU), Sawangii, Wardha, Maharashtra, India. ${ }^{3}$ Department of Conservative Dentistry and Endodontics, Sharad Pawar Dental College, Datta Meghe Institute of Medical Sciences, Deemed to be University (DU), Sawangii, Wardha, Maharashtra, India. ${ }^{4}$ Department of Conservative Dentistry and Endodontics, Sharad Pawar Dental College, Datta Meghe Institute of Medical Sciences, Deemed to be University (DU), Sawangii, Wardha, Maharashtra, India. ${ }^{5}$ Department of Conservative Dentistry and Endodontics, Sharad Pawar Dental College, Datta Meghe Institute of Medical Sciences, Deemed to be University (DU), Sawangii, Wardha, Maharashtra, India. ${ }^{6}$ Department of Conservative Dentistry and Endodontics, Sharad Pawar Dental College, Datta Meghe Institute of Medical Sciences, Deemed to be University (DU), Sawangii, Wardha, Maharashtra, India. ${ }^{7}$ Department of Conservative Dentistry and Endodontics, Sharad Pawar Dental College, Datta Meghe Institute of Medical Sciences, Deemed to be University (DU), Sawangii, Wardha, Maharashtra, India. ${ }^{8}$ Department of Conservative Dentistry and Endodontics, Sharad Pawar Dental College, Datta Meghe Institute of Medical Sciences, Deemed to be University (DU), Sawangii, Wardha, Maharashtra, India.
\end{abstract}

\section{ABSTRACT}

\section{BACKGROUND}

Endodontic therapy is a treatment for the diseased pulp of a tooth. It will result in the removal of infection and the preservation from further microbial invasion. The principle constituents of an endodontic filling are- a core material "gutta percha" and "endodontic sealers". All the current obturating techniques make use of the sealer to augment the seal endodontic filling material. It fills the space between canals. Endodontic sealer fills the space between the material as well as root dentin. Different types of sealers are available (resin sealers, ZOE sealers, mineral trioxide aggregate sealer, bio-ceramic containing sealers, glass ionomer containing sealer, calcium hydroxide containing sealer). Root canal sealers have different functionsantibacterial, lubricant for core material, to increase radio-opacity of core or as a filling material. Different types of microorganisms as well as microbial products cause pulpal as well as peri-radicular diseases. Microorganisms persist in the canal due to poor irrigation. We wanted to evaluate the various functions of different endodontic sealers. The perfect apical seal obtained by use of sealers is one which is stable and non-irritating in nature. It should also give us a smoother seal. Biocompatibility of root canal sealer has importance as it is placed directly in contact with the living tissue. Response of dental tissue help in the final outcome of successful endodontic treatment. Bond strength between canal walls exhibit through micromechanical retention. It helps in preventing the dislodgement of filling material. It ultimately helps in maintenance of interface between filling material and sealers. Push out test is the process to assess bond strength among filling material and sealers. Endodontic sealer has sufficient amount of radiopacity so that it can be clearly visualised among material and adjacent anatomical structures.

\section{KEY WORDS}

Root Canal Sealers, Functions
Corresponding Author:

Dr. Chanchal Harikishor Rathi, Postgraduate Student,

Department of Conservative Dentistry and Endodontics, Room No. 103,

Sharad Pawar Dental College,

Sawangi, Wardha-442001,

Maharashtra, India.

E-mail: chanchalrathidr@gmail.com

DOI: $10.14260 / j e m d s / 2020 / 317$

Financial or Other Competing Interests: None.

How to Cite This Article:

Rathi CH, Chandak M, Nikhade $P$, et al. Functions of root canal sealers- a review. J. Evolution Med. Dent. Sci. 2020;9(17):14541458, DOI: 10.14260/jemds/2020/317

Submission 26-12-2019,

Peer Review 20-02-2020

Acceptance 26-02-2020,

Published 27-04-2020.

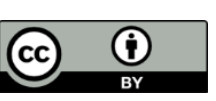




\section{BACKGROUND}

Endodontic therapy is a treatment for the diseased pulp of a tooth. It will result in the removal of infection and the preservation from further microbial invasion. Endodontic treatment is primarily a combination of chemical as well as mechanical preparation of the canal space. It will help in the placement of a biocompatible material. It will provide a threedimensional hermetic seal. The 5 steps of the root canal preparation are-

1. Access cavity preparation.

2. Establishing the glide path for instrumentation.

3. Thorough cleaning of root canal.

4. Thorough irrigation of root canal.

5. 3D obturation of root canal.(1)

The principle constituents of a endodontic filling are: a Core material "Gutta Percha" and "endodontic sealers". All the current obturating techniques make use of the sealer to augment the seal endodontic filling material.(2) It fills space between canals. Endodontic sealer fills space between the material as well as root dentin. Sealers also fills the space between materials as well as accessory canals. Lubrication can be occurred by sealers. So, it help to achieve three dimensional hermetic seal. Basically, sealers have ability of creating bond between the materials as well as dentinal structure.(3) It will prevent the micro leakage. It should not be harmful. It Should help in healing of periapical lesions.(4) Large number and different variety of sealers are available commercially. These sealers are separated in various groups as per chemical ingredient. Fluid tight seal and three dimensional obturation of canal is mandatory. (5) It will provide long-term success in endodontic management. Different types of sealers are available like resin sealers, ZOE sealers, Mineral Trioxide aggregate sealer, Bio-ceramic containing sealers, Glass ionomer containing sealer, calcium hydroxide containing sealer. The root canal sealers have different functions like it has antibacterial property, act as lubricant for core material, increase radio-opacity of core or filling material. So, meaning of this review is to compile functions of different endodontic sealers.

\section{CLASSIFICATION OF ROOT CANAL SEALER}

Based on their principle ingredient-

1. Zinc oxide eugenol containing sealer.

2. Iodoform containing sealer.

3. Calcium hydroxide containing sealer.

4. Resin containing sealer.

5. Polyacrylic acid containing sealer.

6. Silicone based sealer.

7. MTA based sealer.

8. Calcium-silicate-Phosphate containing bioceramic sealers.

9. Calcium-phosphate containing sealers.

\section{Zinc Oxide Eugenol Containing Sealer}

It again divides into eugenol based and non-eugenol-based sealer. Zinc oxide is the main ingredient of all ZOE based sealers. Some of the ZOE based sealer consist of medicated agent like paraformaldehyde, corticosteroids, and heavy metals-

Eugenol Based Sealer

Rickert's formula, Grossmans cement, Wach's cement, Endomethasone, N2

Non-Eugenol Based Sealer

Kloropercha N-0, SPAD

\section{Iodoform Based Sealer}

It was discovered firstly by Walkhoff in 1928. Iodoform is the main ingredient of this sealer- Iodoform paste and Vitapex.

\section{Calcium Hydroxide Based Sealer}

Calcium hydroxide in endodontics first introduced by Herman in 1920. Calcium-hydroxide based sealer used as a sealer as it has good osteogenic and cementogenic properties. It is also helpful in case of periapical lesion as it fastens the periapical healing- Sealapex, Apexit, Apexit plus, Vitapex., Calcibiotic root canal sealer.

\section{Resin Containing Sealer}

Resin containing sealer was introduced in endodontics as it has good physical properties, excellent bonding between "gutta percha" and root canals and excellent apical sealing with minimum microleakage.

\author{
Polyvinyl Resin Based Sealer \\ Diaket, Diaket A.
Methacrylate Resin Containing Sealer
$1^{\text {st }}$ generation (Hydron),
$2^{\text {nd }}$ generation (EndoREZ, Realseal),
$3^{\text {rd }}$ generation (Epiphany, Fibrefill),
$4^{\text {th }}$ generation (Realseal SE, Metaseal SE, Smartseal).

Epoxy Resin Containing Sealer

AH 26 and AH plus.

\section{Polyacrylic Acid Containing Sealer}

Smith and Mc Comb proposed the use of polycarboxylate cement as a root canal sealer. It mainly contains polyacrylic acid as a liquid and zinc oxide as a powder. But it is difficult to remove in case of retreatment cases. So, it has very limited use as a root canal sealer- Polycarboxylate cement, glass ionomer sealer (Ketac Endo).

\section{Silicone Containing Sealer}

Roekoseal, Lee Endofill, Guttaflow.

\section{MTA Containing Sealer}

Endo-CPM-Sealer, MTA Obtura ProRoot, Endo Sealer MTA Fillapex. 
Calcium-Silicate-Phosphate Containing Bioceramic Sealers

Endosequence/iRoot SP, iRoot BP, Bioaggregate.

\section{Calcium-Phosphate Containing Sealers}

Capseal I and Capseal II.

\section{GROSSMAN'S IDEAL REQUIREMENT} OF ENDODONTIC SEALER

1. It should be sticky when mixed and also provide better adhesion.

2. It should provide fluid tight hermetic seal.

3. It should be radiopaque so it can be easily seen on radiographs.

4. It should have small particle size so that it can be easier for mixing.

5. It should not shrink on setting.

6. It must not discolour the tooth.

7. It must have an antibacterial activity.

8. It should not be easily soluble in tissue fluids.

9. It supposed to be not be cytotoxic or mutagenic in nature.

10. It supposed to be biocompatible and non-irritating to periapical or periodontal tissue.

11. It supposed to be easily soluble in routine solvents so that it can be easily removed in retreatment cases.

\section{FUNCTIONS}

\section{Antibacterial Property of Root Canal Sealer}

Different types of microorganism as well as microbial product are the main causative factor in pulpal as well as peri-radicular diseases. The microorganisms present persistently in the canal due to poor irrigation. This insufficient root canal preparation is due to anatomical variations.(6) To decrease or remove the infecting bacteria are adequate root canal debridement, antimicrobial irrigants, and antibacterial filling materials are necessary.(7) Main aim of endodontic management is the removal of bacteria from canal spaces. This is the vital step for successful endodontic management. Because root canal comprises of mixed aerobic- anaerobic microorganism. Use of sealers with antimicrobial activity will be effective in case of persistent infections. The antimicrobial effect of sealers can be evaluated by agar diffusion method. Special types of sealers are available commercially like calcium hydroxide containing sealer, ZOE sealer, resin sealer, calcium silicate sealer, bioceramic sealer.(1) According to (Haapasalo and Orstavik et al) antimicrobial efficacy against microbes was found maximum with $\mathrm{AH}$ plus sealer which is epoxy resin containing sealer, Tubli-Seal which is ZOE based sealer and lesser with Roeko seal which is silicone based sealer.(1) Also antifungal effect of root canal sealer against $C$. albicans is found maximum in case of AH plus sealer followed by MTA Fillapex sealer. But study showed that none of sealer were effective more than 7 days against c. albicans.(4) Some studies shows that the of Easy seal which is zinc oxide containing sealer good antibacterial effect. Also, good antibacterial effect found with EWT sealer. Antibacterial effect was not shown by AH plus sealer and Sealapex after 6 min. But after 15- 60 min they shows good antibacterial effect.(6) Among $\mathrm{AH}$ plus and Sealapex, Sealapex has better antimicrobial activity. This is due to lower release of paraformaldehyde by AH plus sealer. $\mathrm{N} 2$ shows as better antimicrobial action due to zinc-oxide as well as paraformaldehyde. MTA Fillapex shows good bactericidal property on same day. But after 7 days their antibacterial activity gets reduced.(6)

\section{Lubricating Property of Endodontic Sealer}

It is said that influence of lubrication during instrumentation of root canal not popular until 1990.(8) Dentists did not consider irrigants as lubricants.(9) But studies showed that tap water also enhances the cutting efficacy of endodontic files.(10,11) Friction created during instrumentation increases the local temperature. It will ultimately increase the cyclic fatigue of instruments. Use of lubricants lowers the cyclic fatigue by reducing the temperature. Heling I, Chandler NP et al. stated that lubrication is involved in endodontic treatment phases from rubber dam placement to obturation.(12) Many lubricants are introduced for endodontic treatment like sealers, chemical irrigants. These are act as a lubricant. Among those two mainly used types are RC Prep (water-based) and Glyde (glycol-based).(12) Many root canal sealers available in dentistry and these sealers exhibit lubricating properties. Sealer's act as lubricant which helps it to the gutta percha to reach the full length of root canal. As gutta percha is solid core and not flow throughout the canal wall like in lateral canals. So sealer with lubrication property required to easy penetration of gutta percha with sealer throughout the canal for three dimensional impervious seal.(12) Among the different sealers like ZOE containing sealer, calcium hydroxide containing sealer, resin containing sealer, GIC containing sealer, bioceramic containing sealer, MTA containing, zinc oxide eugenol has excellent lubrication property.(6)

\section{Sealing Capability of Endodontic Sealers to Root Dentin}

The most frequently used obturating material is gutta-percha. Gutta percha itself not bind to canal walls.(13) So Sealer is required to fill the interface between them.(14) All current obturating techniques are used to enhance the seal of the endodontic filling.(3) For successful root canal treatment three dimensional sealing is required to minimize microleakage.(15) The perfect apical seal obtained by use of sealers which is stable and non-irritating in nature. Should also give as smoother seal,(15) Superior sealing ability of MTA as Endodontic filling material was given by Zafar M et al.(14) Fluid rigid sealing is the main factor which associated with the success of endodontic management.(16) Ingle et al. (2008) said that $58 \%$ failures of endodontic treatment were due to inadequate obturation. Thus, Different types of root canal sealer commercially available. Currently no sealer has capability to entirely seal the root canal for extensive period of time, $(17,18)$ Jain $\mathrm{P}$ et al. shows that shrinkage after setting $0.3 \%$ to $1 \%$ with zinc oxide eugenol containing sealers.(15) Better sealing ability were shown by $\mathrm{AH}$ plus sealer. Because it expands while setting resulting in tight seal.(19) According to study, among all the sealers "Huang Y et al.1 2018" report that Endosequence which is bioceramic based sealer and AH Plus sealer has outstanding sealing ability to root canal wall 
especially at middle and coronal third of root.(3) Also Ah Plus sealer shows least solubility compared to calcium hydroxide, ZOE sealer, MTA Filapex Sealer.(20)

\section{Biocompatibility of Endodontic Sealer}

Important aim of endodontic treatment is to promote periapical tissue repair by forming cementum like tissue. Biocompatibility of root canal sealer has importance as it is placed directly in contact with living tissue. Response of dental tissue help in final outcome of successful endodontic treatment. Among the various types of sealer which are available commercially, zinc oxide eugenol containing sealer cause moderate type of cytotoxic reaction. According Scarparo et al. resin based sealer showed pronounced cytotoxic reaction, in cell culture but cytotoxic reaction decreases as the material sets. According to Silveira CM et al. calcium hydroxide containing root canal sealer are less cytotoxic than resin based, and ZOE based sealer.(21)

\section{Bond Strength of Root Canal Sealer}

Bond strength between canal walls exhibit through micromechanical retention. It helps to prevent the dislodgement of filling material. It ultimately helps in maintenance of interface between filling material and sealers. Push out test is the process to assess bond strength among filling material and sealers. There are different types of endodontic sealer which demonstrate better bond strength like resin containing sealer, zinc oxide sealer, calcium hydroxide containing sealer. According to Lee et al. resin based sealer exhibit high push out bond strength than MTA Fillapex sealer. According to Madhuri GV et al stated that calcium silicate-based MTA Fillapex sealer shows lesser bond strength than Bioceramic containing Endosequence sealer, Epoxy resin containing sealer (MM-Seal), and Dual cure resin-containing sealer (Hybrid Root Seal). Because it releases calcium and hydroxyl ion which form tag like structure which interfere the bonding between sealer and Filling material.(22) Rosa RA et al stated that when he compared the calcium hydroxide and MTA based sealer. Author found that push out bond strength of calcium hydroxide containing sealer is better than MTA based sealer.(23)

\section{Radio-Opacity of Root Canal Sealer}

Endodontic sealer has sufficient amount of radiopacity so that it can be clearly distinguished among material and adjacent anatomic structure. Radiopacity also calculate the worth of endodontic filling material.(24) "International Organization for Standardization" (ISO) stated that the radiopacity of endodontic sealer supposed to be 3 micrometre of aluminium. Gambarini et al stated that the more radiopaque sealers may cause imperfection in the endodontic material.(25) According to Melahat Gorduysus et al radiopacity of zinc oxide eugenol containing sealer and $\mathrm{AH}$ plus sealer is better than Diaket, Endion, MTA, Endofil, Roeko Seal, AH26 sealer.(24) Sealers when used with gutta percha, they affect the final radioopacity of filling material.(24) M. Tanomaru et.al stated that calcium hydroxide containing sealer shows better radiopacity than GIC based sealer.(26)

\section{CONCLUSIONS}

Apart from the above basic functions, sealer should form a homogenous unit with the dentinal structures and core materials. Also, a concept of creating monoblock within root canal system is proven theoretically.

\section{REFERENCES}

[1] Gupta-Wadhwa A, Wadhwa J, Duhan J. Comparative evaluation of antimicrobial efficacy of three herbal irrigants in reducing intracanal E. Faecalis populations: an in vitro study. Journal of Clinical and Experimental Dentistry 2016;8(3):e230-5.

[2] Patni PM, Chandak M, Jain P, et al. Stereomicroscopic evaluation of sealing ability of four different root canal sealers-an invitro study. Journal of Clinical and Diagnostic Research 2016;10(8):ZC37-9.

[3] Ingle JI. Ingle's Endodontics. $6^{\text {th }}$ edn. Connecticut: Pmph USA Ltd., 2008.

[4] Özcan E, Yula E, Arslanoğlu Z, et al. Antifungal activity of several root canal sealers against Candida albicans. Acta Odontologica Scandinavica 2013;71(6):1481-5.

[5] Huang Y, Orhan K, Celikten B, et al. Evaluation of the sealing ability of different root canal sealers: a combined SEM and micro-CT study. Journal of Applied Oral Science 2018;26: e20160584.

[6] Poggio C, Trovati F, Ceci M, et al. Antibacterial activity of different root canal sealers against Enterococcus Faecalis. Journal of Clinical and Experimental Dentistry 2017;9(6):e743-e8.

[7] Kriplani R, Thosar N, Baliga MS, et al. Comparative evaluation of antimicrobial efficacy of various root canal filling materials along with aloevera used in primary teeth: a microbiological study. Journal of Clinical Pediatric Dentistry 2013;37(3):257-62.

[8] Hülsmann M, Heckendorff M, Lennon A. Chelating agents in root canal treatment: mode of action and indications for their use. International Endodontic Journal 2003;36(12):810-30.

[9] Yguel-Henry S, Vannesson H, Von Stebut J. High precision, simulated cutting efficiency measurement of endodontic root canal instruments: influence of file configuration and lubrication. J Endod 1990;16(9):418-22.

[10] Eggeler G, Hornbogen E, Yawny A, et al. Structural and functional fatigue of NiTi shape memory alloys. Mater Sci Eng A 2004;378:24-33.

[11] Gambarini G, Testarelli L, Pongione G. Radiographic and rheological properties of a new endodontic sealer. Aust Endod J 2006;32(1):31-4.

[12] Heling I, Chandler NP. The antimicrobial effect within dentinal tubules of four root canal sealers. J Endod 1996;22(5):257-9.

[13] Lee KW, Williams MC, Camps JJ, et al Adhesion of endodontic sealers to dentin and gutta-percha. J Endod 2002;28(10):684-8.

[14] Zafar M, Iravani M, Eghbai MJ, et al. Coronal and apical sealing ability of a new endodontic cement. Iran Endod J 2009;4(1):15-9. 
[15] Jain P, Pruthvi V, Sikri VK. An ex vivo evaluation of the sealing ability of polydimethylsiloxane-based root canal sealers. Indian J Dent Res 2014;25(3):336-9.

[16] Torabinejad M, Walton RE. Endodontics: principles and practice. Philadelphia: WB Saunders Co, 2009.

[17] Bouillaguet S, Shaw L, Barthelemy J, et al. Long-term sealing ability of pulp canal sealer, AH-Plus, GuttaFlow and epiphany. Int Endod J 2008;41(3):219-26. f

[18] Balguerie E, van der Sluis L, Vallaeys K, et al. Sealer penetration and adaptation in the dentinal tubules: a scanning electron microscopic study. J Endod 2011;37(11):1576-9.

[19] Royer K, Liu X J, Zhu Q, et al. Apical and root canal space sealing abilities of resin and glass ionomer-based root canal obturation systems. Chin J Dent Res 2013;16(1):4753.

[20] Schäfer E, Zandbiglari T. Solubility of root-canal sealers in water and artificial saliva. Int Endod J 2003;36(10) :660-9.

[21] Silveira CM, Pinto SC, Zedebski RD, et al. Biocompatibility of four root canal sealers: a histopathological evaluation in rat subcutaneous connective tissue. Brazilian Dental Journal 2011;22(1):21-7.
[22] Madhuri GV, Varri S, Bolla N, et al. Comparison of bond strength of different endodontic sealers to root dentin: An in vitro push-out test. Journal of Conservative Dentistry 2016;19(5):461-4.

[23] Rosa RA, Bier CA, Só MV, et al. Push-out bond strength of Calcium hydroxide and Mineral Trioxide Aggregate based sealers to root canal dentin. Journal of Dental Science 2012;27(4):320-4.

[24] Gorduysus M, Avcu N. Evaluation of the radiopacity of different root canal sealers. Oral Surgery, Oral Medicine, Oral Pathology, Oral Radiology and Endodontology 2009;108(3):e135-40.

[25] Tagger M, Katz A. Radiopacity of endodontic sealers: Development of a new method for direct measurement. J Endod 2003;29(11):751-5.

[26] Tanomaru-Filho M, Jorge EG, Goncalves M. Evaluation of the radiopacity of calcium hydroxide and GIC based root canal sealers. Int Endod J 2008;41(1):50-3. 